\title{
DETECTION OF Toxoplasma gondii DNA IN SERA SAMPLES OF MICE EXPERIMENTALLY INFECTED
}

\author{
LANGONI H. (1), DAS DORES C. B. (1), SILVA R. C. (1), PEZERICO S. B. (1), \\ CASTRO A. P. B. (1), DA SILVA A. V. (1)
}

(1) Zoonosis Researches Nucleus, Department of Veterinary Hygiene and Public Health, School of Veterinary Medicine and Animal Husbandry, FMVZ, São Paulo State University, UNESP, Botucatu, São Paulo, Brazil.

ABSTRACT: Detection of Toxoplasma gondii (T. gondii) DNA in blood can help to diagnose the disease in its acute phase; however, it must be considered that hemoglobin, present in blood, can inhibit polymerase activity, making impracticable the detection of DNA in samples. Mice were experimentally infected via oral route with ME49 and BTU2 strains cysts and RH strain tachyzoites; polymerase chain reaction was used to detect $T$. gondii DNA in mice sera 18, 24, 48, 96, and 192 hours post infection (PI). Toxoplama gondii DNA was detected in only one animal infected with BTU2 strain, genotype III (isolated from a dog with neurological signs) 18 hours PI. The agent's DNA was not detected in any sample of the other experimental groups. New studies must be carried out to verify the technique sensitivity in researches on this agent's genetic material using sera samples of acute-phase toxoplasmosis patients, especially in cases of immunosuppression.

KEY WORDS: toxoplasmosis, PCR, serum, experimental infection, mice.

\section{CORRESPONDENCE TO:}

HÉLIO LANGONI, Núcleo de Pesquisas em Zoonoses, Departamento de Higiene Veterinária e Saúde Pública, Faculdade de Medicina Veterinária e Zootecnia, UNESP, Distrito de Rubião Jr., s/n, Caixa Postal 560, 18.618-000, Botucatu, SP, Brasil. Phone: 5514 3811-6270. Fax: 5514 3811-6075.

Email: hlangoni@fmvz.unesp.br. 


\section{INTRODUCTION}

Toxoplasma gondii, the agent of toxoplasmosis, is an obligatory intracellular Apicomplexa parasite that infects warm-blooded animals, being felids the definitive hosts. Toxoplasma gondii presents a heteroxenous life cycle and causes a high number of abortions in many species, mainly ovines. In relation to public health, this parasite is an important cause of abortion in humans too, causing a congenital disease and seriously infecting immunocompromised patients (18).

It presents three genetic lineages - I, II, and III - and reproduces in asexual or sexual form (12). Its virulence varies with the host species. In mice, type I presents greater virulence than the other types, being frequently lethal. Types II and III cause asymptomatic infections, with formation of tissue cysts. In humans, type II infects immunodepressed patients, whereas type I predominantly occurs in cases of congenital infection $(5,6,11)$. Apparently, immunity among them does not exist (2). There are many experimental models of laboratory animals to study this disease. Pathology of infection by $T$. gondii results from the interaction between parasitic factors and the host. It is difficult to compare results, which sometimes are disagreeing, since the experimental models may vary according to the parasite lineage, route of infection, agent's strain, maintenance conditions, and number of parasite passages (21). There are two ways of parasite dissemination by the oral route. In the first form, the parasite reaches the mesenteric circulation and then the liver, reaching the systemic circulation. In the second way, it passes to the lymphatic system and thoracic duct, reaching the systemic circulation; being the latter the most frequent form of dissemination (14).

In relation to immune response in the initial weeks of infection, the organism starts an independent and non-specific response of $\mathrm{T}$ cell and major histocompatibility complex (MHC), using interferon- $\gamma$ (IFN- $\gamma$ ), tumor necrosis factor (TNF), a population of cells from thymus (Thy-1), and natural killer cells (NK). This precocious nonspecific response limits the proliferation of tachyzoites until the specific response dependent on $\mathrm{CD}^{+}$and $\mathrm{CD} 8^{+}$cells is able to protect the animal in chronic infection (8). There are three groups related to $T$. gondii sensitivity grade among the rodents: the most sensitive are Chinese hamster, Syrian hamster, and mice; the moderately sensitive are gerbils and Mastomys; rats are very resistant (7).

Congenital and acute infection has been detected by serological tests, like SabinFeldman test (SF), indirect immunofluorescence test (IFAT), modified agglutination 
test (MAT), hemagglutination test, and enzyme-linked immunosorbent assay (ELISA), which detect the presence of antibodies against $T$. gondii. Specificity and sensitivity of these tests are variable. Other limitation in diagnose is that the amount of antibodies varies with the time of infection and the age of the host (18). Immunocompromised patients, mainly the ones infected by human immunodeficiency virus (HIV), do not present significant titers of IgG and/or IgM anti-Toxoplasma, which makes the diagnosis using these serological tests more difficult (20).

In experimentally infected animals, the presence of $T$. gondii can be investigated by polymerase chain reaction (PCR) too. The techniques used nowadays are aimed, in the majority of cases, at detecting sequences of SAG1 gene, which codifies P30 glycoprotein, the main protein of the membrane of $T$. gondii tachyzoites; sequences of B1 gene, which has a strange function; and parts of DNA-codifying ribosomal RNA (rDNA). In the genome of $T$. gondii, there is only one copy of SAG1 gene, 35 copies of $B 1$ gene, and 110 copies of genes to rDNA, which in part explains the differences found in the sensitivity of many PCR protocols to detect Toxoplasma (5). Homan et al. (11) described a new repeated sequence, with 200-300 copies in the genome of T. gondii, which when used in PCR demonstrated sensitivity higher than that of B1 gene.

Weiss et al. (20) demonstrated that DNA of $T$. gondii RH strain can be detected by PCR in tissues of acute-toxoplasmosis mice with high specificity and sensitivity inferior or equal to ten tachyzoites. Parasite was detected in tissues on the second day and in blood, 15 days PI. Using a protocol of nested PCR to detect this agent's B1 gene in blood samples of infected mice, Joss et al. (13) observed that with $\mathrm{RH}$ strain, 18 from 20 animals tested 16-66 hours PI were positive to PCR and the bioassay. Among 24 animals infected with Beverley strain, only two had the parasite reisolated in the bioassay, resulting in positive PCR for 15 animals from 1 to 38 days $\mathrm{PI}$.

In Swiss mice infected by oral route with cysts of $C$ strain isolated from human placenta, Paugam et al. (14) tested two PCR protocols for the detection of parasitemia. One directed to $B 1$ gene and the other to $T G R_{1} E$ repetitive sequence. PCR-B1 detected parasitemia from 48 hours to the seventh day PI, whereas PCR$\mathrm{TGR}_{1} \mathrm{E}$ detected it until the twenty-first day.

Rodríguez et al. (15) collected serum and cerebro-spinal fluid of 70 immunocompetent and asymptomatic patients with previous toxoplasmosis; 70 
immunocompetent patients without toxoplasmosis; 63 carriers of HIV with encephalitis but not toxoplasmic; 5 patients under anti-Toxoplasma therapy and with cerebral toxoplasmosis; and 11 patients not under therapy and without cerebral toxoplasmosis. They performed PCR-B1 followed by hybridization with a chemiluminescent probe; serology to detect $\lg G$, $\lg M$, and $\lg A$ levels; and detection of circulating antigen. The technique of PCR presented the best results: $62 \%$ sensitivity and $100 \%$ specificity with five tachyzoites per sample as detention limit. In a similar study, Hafid et al. (10) detected the agent's DNA in sera of mice infected with T. gondii RH strain. Five animals were killed 3, 6, 9, 12, 15, 18, and 24 hours PI and then daily until the seventh day. In $60 \%$ of the animals, the agent was detected 18 hours PI, and in 100\%, from 24 hours until the seventh day PI. The detention limit of the agent was two tachyzoites in $200 \mu$ l.

Comparison between PCR-B1, and ELISA and immunoblotting tests carried out by Hafid et al. (9) in serum samples of experimentally infected mice showed that PCR was positive 18 hours $\mathrm{PI}$, whereas the other methods were positive only 24 hours PI. Amplification of B1 gene by PCR has demonstrated to be more sensitive and faster than ELISA, immunoblotting and cell culture. The authors discussed that sensitivity of the results can depend on the strain, inoculation dose, and PCR protocol used.

Using sera samples to detect $T$. gondii DNA in the acute phase of infection can be more advantageous compared to serological methods due to sensitivity, as well as to the fact of being a direct demonstration of the parasite. On the other hand, the use of sera as an alternative to total blood samples gives as advantages the minor concentration of probable agents that interfere in PCR, facilitating the obtainment of higher-quality DNA. Therefore, the experiment protocols used until the moment have not been based on situations similar to $T$. gondii natural infection by using tachyzoites via intraperitoneal route, an effective artificial route. Thus, the objective of the present study was to verify the presence of $T$. gondii DNA in sera samples of mice infected with tissue cysts of three genetically different strains.

We have to consider the presence of hemoglobin and to be careful in the extraction of samples contaminated by this blood component. Hemoglobin can inhibit PCR because the connection between the groups heme and/or perforin and Taq DNA polymerase inactivates the enzyme. Hemoglobin and lactoferrin were found to be major PCR inhibitors in erythrocytes and leukocytes, respectively. Both hemoglobin and lactoferrin contain iron. Therefore, the inhibitory effects of both proteins may be 
related, in part, because of their ability to release iron ions. Hemin, a hemoglobin derivative, and its breakdown products, bilirubin and bile salts, were also found to be PCR inhibitors. It has been suggested that heme regulates DNA polymerase activity and coordinates the synthesis of hemoglobin components in erythroid cells by feedback inhibition (1). To solve this problem, PCR inhibitors should be inactivated or removed from the sample.

\section{MATERIAL AND METHODS}

We used RH strain tachyzoites, genotype I - isolated from a child from the United States by Sabin in 1939 (16) - which were weekly inoculated by intraperitoneal route in albino Swiss mice. To obtain the tissue cysts and free bradyzoites for the inoculation, the strains ME49, genotype II (17), and BTU2, genotype III, isolated from a dog with neurological signs, were used. The cysts were obtained by orally inoculating 10 albino Swiss mice, female, 50-80g, with 20 tissue cysts of T. gondii ME49 and BTU2 strains. Animals were treated with sulfadiazine (400mg sulfadiazine $+10 \mathrm{~g}$ sodium bicarbonate/liter of water) in drink water from the third to the twentieth day PI to induce chronic infection (19). Two months PI, they were killed in a chamber saturated of isoflurane vapor. Cysts purification was performed according to Dubey (4). All animals were gently supplied by Central Animal Facility, UNESP, Botucatu, São Paulo.

Brains were obtained with thorough antisepsis and washed with $0.85 \%$ saline solution ( $5 \mathrm{ml} / \mathrm{brain}$ ) in order to remove red blood cells; they were kept in $0.85 \%$ saline solution ( $4 \mathrm{ml} / \mathrm{brain})$ at $4^{\circ} \mathrm{C}$ for 12 hours, macerated and mixed from seven to eight times using syringe and needle. The suspension was transferred to a $50 \mathrm{ml}$-centrifuge tube containing $8 \mathrm{ml}$ of $25 \%$ Percoll ( $2 \mathrm{ml}$ Percoll $+6 \mathrm{ml}$ saline/brain) and centrifuged at $2000 \mathrm{~g}$ for 30 minutes in "brake off" position. The cerebral material was carefully removed as well as the rest of the Percoll suspension, except for the final $0.5 \mathrm{ml}$. In order to resuspend the sediment, $10 \mathrm{ml}$ of $0.85 \%$ saline solution was added, followed by centrifugation at $1200 \mathrm{~g}$ for 10 minutes in "brake off" position. Supernatant was discarded, sediment was resuspended in $1 \mathrm{ml}$ of $0.85 \%$ saline solution, and cysts in samples of $8 \mu$ of the suspension were counted in an optic microscope. The cysts concentration was calculated using the formula: number of cysts counted / (16x1000). To obtain tissue cysts of RH strain, four Fischer rats were infected, 
because this species develops chronic infection by genotype I strains easier than the others. Rats are naturally more resistant to infection caused by $T$. gondii.

Release of bradyzoites from the interior of the cysts was performed according to Dubey (8), completing the volume of the cysts suspension to $10 \mathrm{ml}$ with $0.85 \%$ saline solution; an equal volume of pepsin acid solution previously maintained at $37^{\circ} \mathrm{C}$ was added, followed by incubation for five minutes under constant agitation. The suspension was neutralized with $1.2 \%$ sodium bicarbonate and centrifuged at $1200 \mathrm{~g}$ for 10 minutes. Supernatant was discarded and the sediment was resuspended with $0.85 \%$ saline solution to $1 \mathrm{ml}$. Bradyzoites were counted in a Neubauer chamber. The concentration of bradyzoites was adjusted to $10^{4}$ in $100 \mu$ of suspension.

In experimental groups, we also used albino Swiss mice, female, weighting 50-80g. Four groups of animals were used: G1, with 15 mice infected by oral route with $10^{4}$ tachyzoites of RH strain (genotype I); G2, with 15 mice infected by oral route with $10^{4}$ bradyzoites of ME49 strain (genotype II); G3, with 15 mice infected by oral route with $10^{4}$ bradyzoites of BTU2 strain (genotype III); and G4, with 5 mice injected by oral route with $100 \mu$ of sterile saline solution (control group). Sera samples were collected from each experimental group, and blood was collected by retro-orbital sinus puncture from three mice 18, 24, 48, 96, and 192 hours PI. Serum was obtained by sedimentation and kept in microtubes at $-80^{\circ} \mathrm{C}$ until analysis.

Polymerase chain reaction was carried out using the primers described by Homan et al. (11), which amplify a sequence of 529 base pairs (bp) of $T$. gondii nuclear genome. PCR protocol was performed according to Da Silva \& Langoni (3), changing the concentration of $\mathrm{MgCl}_{2}$, deoxynucleotides and primers. Initially, various protocols of DNA extraction from the serum were compared. Toxoplasma gondii AS28 strain tachyzoites $\left(10^{3}, 10^{2}, 10^{1}\right.$, and $\left.10^{\circ}\right)$ were added to the sera samples of not-infected mice, testing the following protocols of DNA extraction:

\section{Protocol 1}

Serum sample $(250 \mu \mathrm{l})$ added of $250 \mu \mathrm{l}$ phenol was vigorously homogenized in vortex and centrifuged at $13200 \mathrm{~g}$ for three minutes. After this, $200 \mu \mathrm{l}$ of the aqueous phase was carefully transferred to a new microtube of $1.5 \mathrm{ml}$ plus $100 \mu \mathrm{l}$ of phenol:chloroform:isoamilic alcohol (25:24:1), homogenized and centrifuged as previously described. The aqueous phase $(100 \mu \mathrm{l})$ was transferred to a new 
microtube of $1.5 \mathrm{ml}$, with the addition of $18 \mu \mathrm{l}$ of $2 \mathrm{M}$ sodium acetate and $236 \mu \mathrm{l}$ of frozen absolute ethanol; the microtubes were kept at $-80^{\circ} \mathrm{C}$ for one hour. The samples were centrifuged at $13200 \mathrm{~g}$ for ten minutes, ethanol was carefully spilled, and $236 \mu \mathrm{l}$ of $70 \%$ ethanol was added. After homogenization, the samples were centrifuged at $13200 \mathrm{~g}$ for ten minutes, ethanol was removed, and microtubes were dried to environment temperature. They were resuspended in $100 \mu$ of ultrapure water, incubated at $56^{\circ} \mathrm{C}$ for 30 minutes, and kept at $-20^{\circ} \mathrm{C}$ until PCR.

\section{Protocol 2}

First, sera samples were incubated at $56^{\circ} \mathrm{C}$ for one hour with $250 \mu \mathrm{l}$ of extraction buffer solution (200mmol HCl, $20 \mathrm{mmol}$ Tris, pH8.0, $50 \mathrm{mmol}$ EDTA, pH8.0), $1 \mathrm{mg} / \mathrm{ml}$ of proteinase $\mathrm{K}$, and $2 \%$ of sodium dodecyl sulfate (SDS). Then, the conduct adopted in protocol 1 was followed.

\section{Protocol 3}

Initially, sera samples were incubated at $100^{\circ} \mathrm{C}$ for 15 minutes with $250 \mu$ of the buffer solution described in protocol 2, without addition of proteinase $\mathrm{K}$ and SDS. Afterwards, the previously described conducts were carried out.

\section{Protocol 4}

In the beginning, $100 \mu \mathrm{l}$ of serum was homogenized with sodium acetate and ethanol, and then protocol 1 conducts were performed.

\section{Protocol 5}

First, $100 \mu \mathrm{l}$ of serum was homogenized with $1000 \mu \mathrm{l}$ of DNAzol extraction reagent (Invitrogen ${ }^{\circledR}$ ) and centrifuged at $10000 \mathrm{~g}$ for 10 minutes. Supernatant was transferred to a new microtube, and $500 \mu$ l of absolute ethanol was added for DNA precipitation. The previously described conducts were maintained.

For PCR, each $0.5 \mathrm{ml}$-reaction tube received $5 \mu \mathrm{l}$ of PCR buffer $(50 \mathrm{mmol} \mathrm{KCl}, 10 \mathrm{mmol}$ Tris- $\mathrm{HCl}), 1.5 \mu \mathrm{l}$ of $\mathrm{MgCl}_{2}(1.5 \mathrm{mmol}), 8 \mu \mathrm{l}$ of deoxynucleotides solution $(1.25 \mathrm{mmol})$, $0.15 \mathrm{U}$ of Taqpolymerase, $10 \mathrm{pmol}$ of primers TOX4 (5'CGCTGCAGGGAGGAAGACGAAAGTTG3') and TOX5 
(5'CGCTGCAGACACAGTGCATCTGGATT3'), 10 $\mu \mathrm{l}$ of sample, and $15.2 \mu \mathrm{l}$ of ultrapure water. Samples were subjected to amplification in a thermal cycler (Gene Cycler) BIO-RAD ${ }^{\circledR}$, with a initial cycle of $94^{\circ} \mathrm{C} / 7 \mathrm{~min}$, followed by 35 cycles of $94^{\circ} \mathrm{C} / 1$ $\min , 60^{\circ} \mathrm{C} / 1 \mathrm{~min}$, and $72^{\circ} \mathrm{C} / 1 \mathrm{~min}$, with a final extension to $72^{\circ} \mathrm{C} / 10 \mathrm{~min}$ (11). After PCR, the samples were subjected to electrophoresis in $1.5 \%$ agarose gel in TrisBorate-EDTA buffer, and then stained with ethidium bromide and a band of 529bp was visualized under an ultraviolet transluminator.

\section{RESULTS AND DISCUSSION}

Figure 1 presents the results of PCRs in sera samples contaminated with $10^{3}, 10^{2}$, $10^{1}$, and $10^{0}$ tachyzoites of T. gondii AS28 strain. Protocol 3 showed an analytical sensitivity of one parasite in $250 \mu$ l sample, while protocols 1 and 2 showed 100 and 1000 parasites in $250 \mu$ l sample, respectively. Protocol 5 revealed an analytical sensitivity of 40 parasites in $100 \mu$ sample. PCR was not carried out in samples extracted by protocol 4 because when the alcohol and the sodium acetate were homogenized to the sera sample, precipitation occurred, making the purification of DNA impracticable. Thus, we used protocol 3 for extracting DNA of the sera samples studied.

As demonstrated in Figure 2, detection of $T$. gondii DNA in the samples, referring to the first moment of collection, that is 18 hours $\mathrm{PI}$, was possible in G3 animals, which were infected with BTU2 strain, genotype III, isolated from a dog with neurological signs.

Results were different from those of Hafid et al. (10), who after inoculating $10^{3}$ tachyzoites of $\mathrm{RH}$ strain via intraperitoneal route, obtained $60 \%$ sensitivity 18 hours $\mathrm{PI}$, and $100 \%$ from 21 hours to the seventh day PI. Detection of only one positive sample 18 hours PI in the group infected with BTU2 strain could be explained by the inoculation route, the infecting form, the virulence of the strain, the individual susceptibility, and the mice lineage. Intraperitoneal route shows a lower number of barriers for the parasite to reach the lymphatic and hematogenic route, compared to the oral route. Tachyzoites present active penetration into the organs, but bradyzoites need to break the cyst and transform themselves again into tachyzoites to cause the infection, which can influence the results because PCR disfavor the detection of $T$. gondii in the first hours PI, in other words, during the acute phase. We believe that the mice lineage was the predominant factor to detect $T$. gondii DNA in 
only one sample collected 18 hours PI. The lineage used is not considered isogenic, so no mouse could respond similarly in the same conditions of the experiment.

Group 3 was, therefore, the one that most developed the disease, with death before 192 hours PI, which suggests major infectivity and virulence by BTU2 strain via oral route. The results obtained can also be explained by the large individual variability of the group, because the animals were not isogenic.

Performing PCR from the serum of infected animals has the advantage of using material with minor quantity of agents that can interfere in the reaction. With the results obtained in the conditions of the present work, PCR did not show to be an efficient method in detecting the parasite DNA. Thus, new studies with other samples of $T$. gondii are needed to explain the validity of researches on this agent in serum of animals, as well as of human patients in the acute phase of infection, and mainly in cases of reactivation of toxoplasmosis, like in immunosuppression. An important fact would be to consider intraperitoneal route as the infection route of tachyzoites, comparing the results in the same studied moments, in albino Swiss mice as well as in those of isogenic lineage.

We concluded that serum is a great tool for diagnosing $T$. gondii infection, since it is not so invasive like the others; however, it must be further investigated in experimental groups to detect infection in earlier periods. 


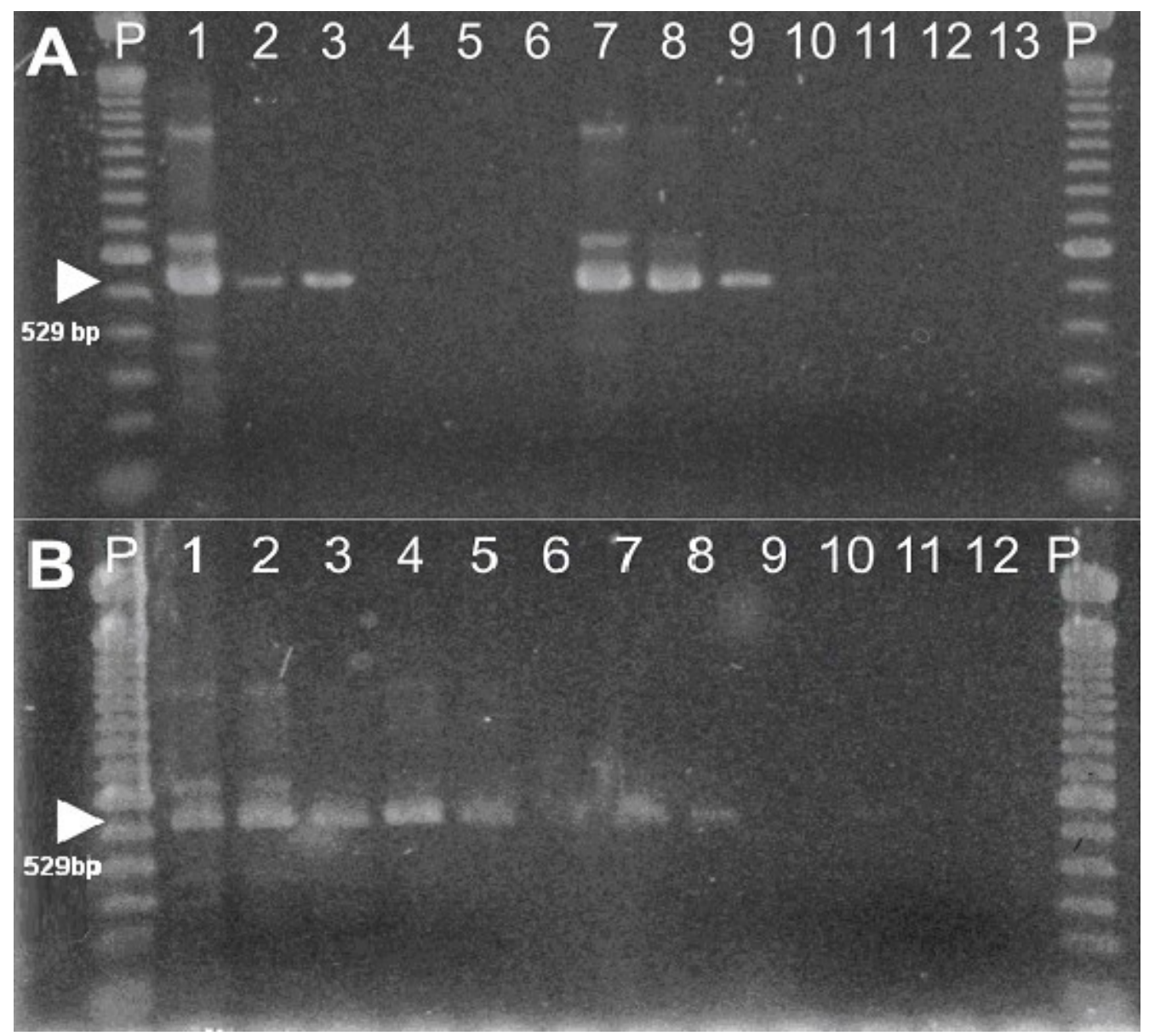

Figure 1: Polymerase chain reaction (PCR) for detection of Toxoplasma gondii DNA in sera samples contaminated with $10^{3}, 10^{2}, 10^{1}$, and $10^{0}$ tachyzoites. Botucatu, 2005.

A - Lanes: P - 100bp DNA-Ladder $\left(\right.$ Gibco $\left.^{\circledR}\right)$, molecular weight marker; 1 - positive control (AS28 strain); 2 - serum with $10^{3}$ tachyzoites (protocol 1); 3 - serum with $10^{2}$ tachyzoites (protocol 1); 4 - serum with $10^{1}$ tachyzoites (protocol 1); 5 - serum with $10^{0}$ tachyzoites (protocol 1); 6 - serum without tachyzoites; 7 - serum with $10^{3}$ tachyzoites (protocol 2); 8 - serum with $10^{2}$ tachyzoites (protocol 2); 9 - serum with $10^{1}$ tachyzoites (protocol 2); 10 - serum with $10^{0}$ tachyzoites (protocol 2); 11 - serum without tachyzoites; 12 - Tris-NaCl-EDTA (TNE); 13 - ultrapure water (mix-PCR control).

B - Lanes: P - 100bp DNA-Ladder $\left(\right.$ Gibco $\left.^{\circledR}\right)$, molecular weight marker; 1 - positive control (AS28 strain); 2 - serum with $10^{3}$ tachyzoites (protocol 3); 3 - serum with $10^{2}$ tachyzoites (protocol 3); 4 - serum with $10^{1}$ tachyzoites (protocol 3); 5 - serum with $10^{0}$ tachyzoites (protocol 3); 6 - serum without tachyzoites; 7 - serum with 400 tachyzoites (protocol 2); 8 - serum with 40 tachyzoites (protocol 2); 9 - serum with 4 tachyzoites (protocol 2); 10 - serum with $10^{0}$ tachyzoite (protocol 2); 11 - serum without tachyzoites; 12 - ultrapure water (mix-PCR control). 


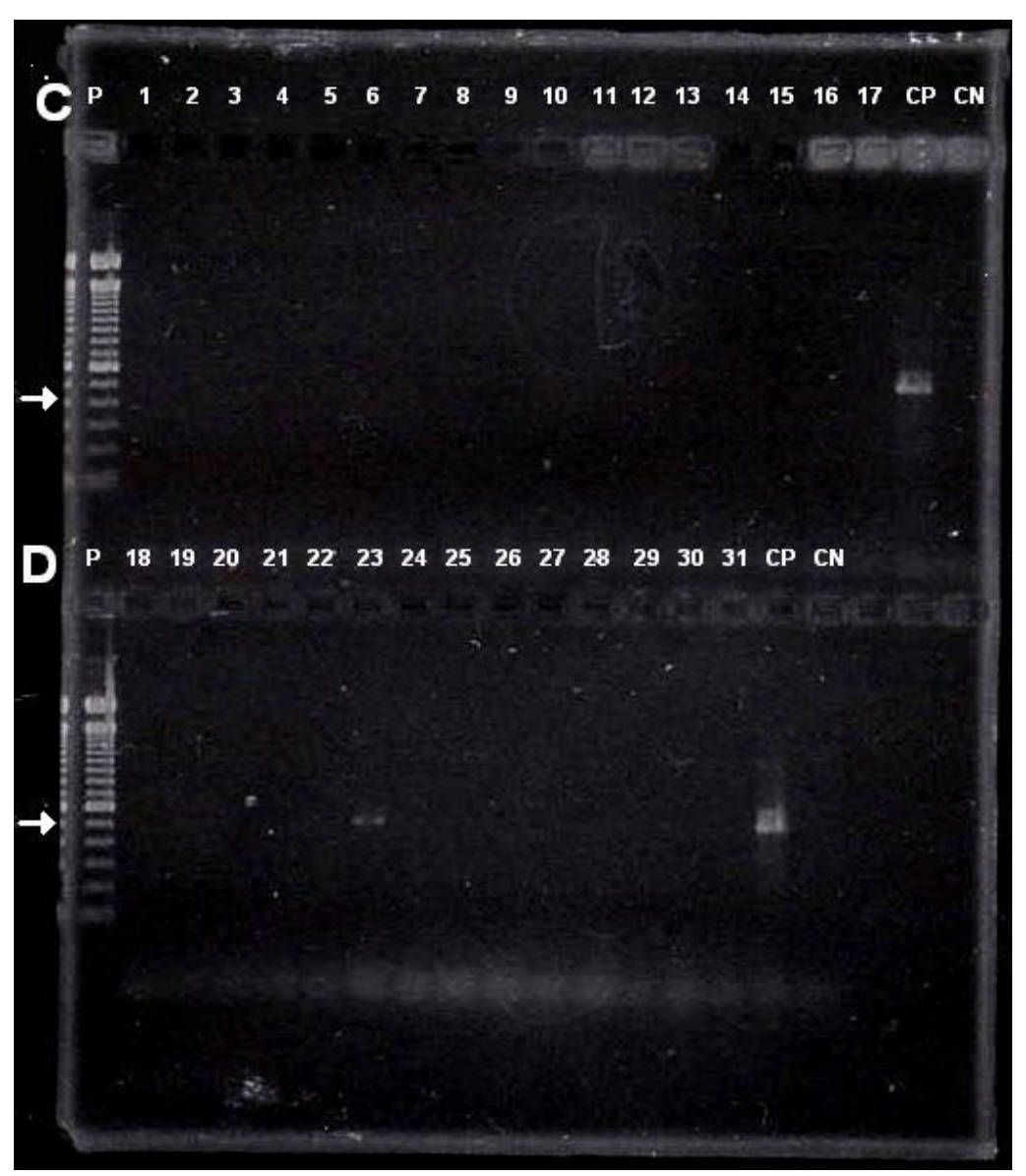

Figure 2: Polymerase chain reaction (PCR) to detect Toxoplasma gondii DNA in G1, G3 and G4 sera samples. Botucatu, 2005.

C - Lanes: P - 100bp DNA-Ladder $\left(\right.$ Gibco $\left.^{\circledR}\right)$, molecular weight marker; 1, 2 and 3 - G1 samples 18h PI; 4 - G4 sample $18 \mathrm{~h} \mathrm{Pl} ; 5,6$ and 7 - G1 samples 24h PI; 8 - G4 sample 24h PI; 9, 10 and 11 - G1 samples $48 \mathrm{~h} \mathrm{Pl} ; 12$ - G4 sample 48h Pl; 13 negative control of the DNA extraction protocol; 14,15 and $16-\mathrm{G} 1$ samples $96 \mathrm{~h} \mathrm{PI}$; 17 - G4 sample 96h PI; CP - positive control of PCR; CN - negative control of PCR.

D - Lanes: P - 100bp DNA-Ladder (Gibco ${ }^{\circledR}$ ), molecular weight marker; 18, 19 and 20 - G1 samples 192h PI; 21 - G4 sample 192h PI; 22, 23 and 24 - G3 samples 18h PI; 25 - negative control of the DNA extraction protocol; 26, 27 and 28 - G3 samples 24h $\mathrm{PI}$; 29, 30 and 31 - G3 samples 48h PI.

$\mathrm{G} 1=15$ mice infected by oral route with $10^{4}$ tachyzoites of $\mathrm{RH}$ strain (genotype I).

G3 $=15$ mice infected by oral route with $10^{4}$ bradyzoites of BTU2 strain (genotype III).

G4 $=5$ mice injected by oral route with $100 \mu$ l of sterile saline solution (control group). 


\section{REFERENCES}

1 AL-SOUD WA., RADSTROM P. Purification and characterization of PCR-inhibitory components in blood cells. J. Clin. Microbiol., 2001, 39, 485-93.

2 ARAUJO F., SLIFER T., KIM S. Chronic infection with Toxoplasma gondii does not prevent acute disease or colonization of the brain with tissue cysts following reinfection with different strains of the parasite. J. Parasitol., 1997, 83, 521-2.

3 DA SILVA AV., LANGONI $\mathrm{H}$. The detection of Toxoplasma gondii by comparing cytology, histopathology, bioassay in mice, and the polymerase chain reaction (PCR). Vet. Parasitol., 2001, 97, 191-8.

4 DUBEY JP. Comparative infectivity of Toxoplasma gondii bradyzoites in rats and mice. J. Parasitol., 1998, 84, 1279-82.

5 ELLIS JT. Polymerase chain reaction approaches for the detection of Neospora caninum and Toxoplasma gondii. Int. J. Parasitol., 1998, 28, 1053-60.

6 FUENTES I., RUBIO JM., RAMIREZ C., ALVAR J. Genotypic characterization of Toxoplasma gondii strains associated with human toxoplasmosis in Spain: direct analysis from clinical samples. J. Clin. Microbiol., 2001, 39, 1566-70.

7 FUJII H., KAMIYAMA T., HAGIWARA T. Species and strain differences in sensitivity to Toxoplasma infection among laboratory rodents. Jpn. J. Med. Sci. Biol., 1983, 36, 343-6.

8 GUY EC., JOYNSON DH. Potential of the polymerase chain reaction in the diagnosis of active Toxoplasma infection by detection of parasite in blood. $\mathrm{J}$. Infect. Dis., 1995, 172, 319-22.

9 HAFID J., FLORI P., RABERIN H., TRAN MANH SUNG R. Comparison of PCR, capture ELISA and immunoblotting for detection of Toxoplasma gondii in infected mice. J. Med. Microbiol., 2001, 50, 1100-4.

10HAFID J., GUICHARD D., FLORI P., BOURLET T., RABERIN H., GENIN C., SUNG RT. Detection of Toxoplasma gondii by polymerase chain reaction in sera of acutely infected mice. J. Parasitol., 2000, 86, 857-9.

11 HOMAN WL., VERCAMMEN M., DE BRAEKELEER J., VERSCHUEREN H. Identification of a 200- to 300-fold repetitive 529bp DNA fragment in Toxoplasma gondii, and its use for diagnostic and quantitative PCR. Int. J. Parasitol., 2000, 30, 69-75. 
12 HOWE DK., SIBLEY LD. Toxoplasma gondii comprises three clonal lineages: correlation of parasite genotype with human disease. J. Infect. Dis., 1995, 172, 1561-6.

13 JOSS AW., CHATTERTON JM., EVANS R., HO-YEN DO. Toxoplasma polymerase chain reaction on experimental blood samples. J. Med. Microbiol., 1993, 38, 38-43.

14 PAUGAM A., DUPOUY-CAMET J., SUMUYEN MH, ROMAND S., LAMORIL J., DEROUIN F. Detection of Toxoplasma gondii parasitemia by polymerase chain reaction in perorally infected mice. Parasite, 1995, 2, 181-4.

15 RODRIGUEZ JC., MARTINEZ MM., MARTINEZ AR., ROYO G. Evaluation of different techniques in the diagnosis of Toxoplasma encephalitis. J. Med. Microbiol., 1997, 46, 597-601.

16 SABIN AB. Toxoplasmic encephalitis in children. J. Amer. Med. Assoc., 1941, 116, 801-7.

17 SUZUKI Y., CONLEY FK., REMINGTON JS. Importance of endogenous IFNgamma for prevention of toxoplasmic encephalitis in mice. J. Immunol., 1989, $143,2045-50$.

18 TENTER AM., HECKEROTH AR., WEISS LM. Toxoplasma gondii: from animals to humans. Int. J. Parasitol., 2000, 30, 1217-58.

19 VILLARD O., CANDOLFI E., FERGUSON DJ., MARCELLIN L., KIEN T. Loss of oral infectivity of tissue cysts of Toxoplasma gondii $\mathrm{RH}$ strain to outbred Swiss Webster mice. Int. J. Parasitol., 1997, 27, 1555-9.

20 WEISS LM., UDEM SA., SALGO M., TANOWITZ HB., WITTNER M. Sensitive and specific detection of Toxoplasma DNA in an experimental murine model: use of Toxoplasma gondii-specific cDNA and the polymerase chain reaction. J. Infect. Dis., 1991, 163, 180-6.

21 ZENNER L., DARCY F., CAPRON A., CESBRON-DELAUW MF. Toxoplasma gondii: Kinetics of the dissemination in the host tissues during the acute phase of infection of mice and rats. Exp. Parasitol., 1998, 90, 86-94. 